\title{
SISTEM PENDUKUNG KEPUTUSAN PENENTUAN PENERIMA BEASISWA PADA SMK MADYATAMA DENGAN METODE TOPSIS
}

\author{
Ani Sunalia ${ }^{1}$, Leon Andretti Abdillah ${ }^{2 *}$, Suyanto $^{3}$ \\ 1,2,3 Program Studi Sistem Informasi, Universitas Bina Darma \\ 1,2,3 Jalan Ahmad Yani No.3, Plaju, Palembang \\ ${ }^{1}$ anisunalia94@gmail.com, ${ }^{2 *}$ leon.abdillah@yahoo.com, ${ }^{3}$ suyanto@binadarma.ac.id
}

\begin{abstract}
Data processing in the determination of scholarships in SMK Madyatama to date still use a system that is still manual. Where the absence of a well-computerized system in determining the acceptance of scholarship which then led to the emergence of some problems in this manual system. The problem that often arises is not exactly the distribution of scholarships to students. Problems like this are triggered by the lack of scrutiny of the scholarship selectors in conducting the selection process of the scholarship recipients, which is basically the selection process conducted by teachers from the school itself. The decision-making system at SMK Madyatama will be made using TOPSIS method to determine the right scholarship recipient in accordance with the scholarship recipient criteria. With the decision support system of awarding scholarship recipients at SMK Madyatama Palembang based on this website can help and facilitate the school in evaluating the selection of scholarship receipt.
\end{abstract}

Keywords: DSS, TOPSIS, Scholarships, SMK Widyatama.

\section{PENDAHULUAN}

Sistem yang terkomputerisasi adalah sistem informasi yang sudah terintegrasi dengan baik agar dapat mendukung keputusan. Sistem informasi (SI) terdapat beberapa bagian seperti Sistem Pemrosesan Transaksi (Transaction Processing Systems), Sistem Otomastisasi Kantor (Office Automation Systems), Sistem Informasi Manajemen (Management Information System), Sistem Pendukung Keputusan (Decision Support Systems), Sistem Informasi Manajemen (Management Information System), Sistem Ahli (Expert System) dan Kecerdasan Buatan (Artificial Intelegent).

Sistem Pendukung Keputusan (SPK) merupakan sebuah sistem yang mampu memberikan kemampuan baik pemecahan masalah maupun kemampuan pemgkomunikasian untuk masalah semi-terstruktur. Secara khusus, SPK didefinisikan sebagai sebuah sistem yang mendukung kerja seorang manajer maupun sekelompok manajer dalam memecahkan masalah semi-terstruktur dengan cara memberikan informasi ataupun usulan menuju pada keputusan tertentu (Hermawan, 2005). Sistem pendukung keputusan (SPK) adalah sistem yang dibangun untuk menentukan sebuah alternatif dari beberapa pilhan yang ada guna untuk membantu pimpinan dalam pengambilan keputusan. Dalam SPK dikenal sejumlah metode yaitu Simple Additive Weighting Method (SAW), Analytic Hierarchy Process Method (AHP), Fuzzy, Profile Matching Method (PM), dan salah satunya adalah metode Technique for Order by Similarity to Ideal Solution Method (TOPSIS) (Fan \& Cheng, 2009).

TOPSIS adalah salah satu metode dalam sistem informasi pengambilan keputusan, TOPSIS memiliki karakteristikdimana ketika nilai kriteria tersebut semakin besar maka semakin layak pula untuk di pilih. Sedangkan kriteria biaya merupakan kebalikan dari kriteria manfaat, semakin kecil nilai dari kriteria tersebut maka akan semakin layak untuk dipilih. Dalam metode TOPSIS, alternatif yang optimal adalah yang paling dekat dengan solusi ideal positif dan paling jauh dari solusi ideal negatif.

Ada sejumlah penelitian terdahulu yang dijadikan acuan oleh penulis untuk melakukan penelitian ini adalah: 1) Sistem Pendukung Keputusan Kelayakan TKI Ke Luar Negeri Menggunakan FMADM (Ariani, Abdillah, \& Syakti, 2013). SPK ini dibuat untuk menentukan kelayakan TKI keluar Negeri. Proses penyeleksian calon TKI menggunakan metode FMADM. SPK yang dihasilkan mampu melakukan perangkingan terhadap calon TKI, sehingga memudahkan pihak BP3TKI dalam mengambil keputusan mengenai TKI yang akan diberangkatkan ke luar negeri, 2) SPK Seleksi Penerima Beasiswa Untuk Siswa Berprestasi Menggunakan Metode Topsis (Jumiati, 2013). Siswa yang mengikuti serangkaian tahapan seleksi yang diberikan berdasarkan kriteria Prestasi Rapor dan Pendapatan Wali Murid. Nilai yang diperhitungkan adalah 3 nilai tertinggi dari setiap kelasnya yaitu peringkat 1, peringkat 2 dan peringkat 3 . Setelah didata maka Siswa yang terpilih mendapatkan beasiswa akan diberikan oleh wali kelas setiap 
penerimaan rapor dalam setiap semesternya, 3) Sistem Pendukung KeputusanPemberian Beasiswa Bidik Misi (Umami, Abdillah, \& Yadi, 2014). Penelitian ini dibuat untuk memudahkan proses seleksi beasiswa "Bidik Misi" dengan metode SAW. Kriteria untuk beasiswa ini melibatkan indeks prestasi akademik, penghasilan orang tua, orang tua tanggungan nomor, semester, dll Penulis juga digunakan air terjun model approach untuk mengembangkan sistem. Hasilnya adalah sebuah sistem pendukung keputusan yang dapat membantu keputusan membuat cepat dan sesuai dengan aturan Beasiswa Bidik Misi, 4) Sistem Penunjang Keputusan Kelayakan PemberianPinjaman Dengan Metode Fuzzy Tsukamoto (Murti, Abdillah, \& Sobri, 2015). Penelitian ini membahas tentang SPK pinjaman. Sistem ini digunakan untuk membantu penyelesaikan permasalahan atau pengambilan keputusan yang bersifat semi terstruktur atau terstruktur. Metode yang digunakan adalah fuzzy tsukamoto. Untuk mempercepat waktu pemrosesan maka dikembangkanlan SPK dengan metode fuzzy tsukamoto, dan 5) SPK Penerima Beasiswa Dengan Metode TOPSIS di Universitas Sam Ratulangi Manado (Wijaya, Wowor, \& Tulenan, 2015). Hal-hal yang harus dipertimbangkan antara lain: kapasitas penerima, pemenuhan persyaratan berupa berkas, kemampuan ekonomi serta kompetensi akademik sesuai dengan ketentuan masing-masing program beasiswa. SPK penerima beasiswa dengan metode TOPSIS dapat secara objektif membantu pengambilan keputusan penerima beasiswa berdasarkan kriteria-criteria sebagai berikut: Kartu Mahasiswa, Piagam atau bukti prestasi lainnya, Kartu Keluarga, Surat Keterangan Tidak Mampu dari Kelurahan, dan IPK.

Madyatama merupakan salah satu Sekolah Menengah Kejuruan (SMK) swasta yang memberikan beasiswa kepada mahasiswa setiap semester. Beasiswa adalah bentuk penghargaan yang diberikan kepada individu untuk melanjutkan pendidikan ke jenjang yang lebih tinggi. Penghargaan itu dapat berupa akses tertentu pada suatu institusi atau penghargaan berupa bantuan keuangan (Murniasih, 2009). Tujuan pemberian beasiswa adalah untuk meringankan beban biaya pendidikan siswa. Program Beasiswa yang diberikan oleh SMK Madyatama salah satunya adalah beasiswa unggulan. Beasiswa unggulan membebaskan biaya sekolah untuk calon siswa yang kurang berkecukupan dari segi ekonomi namun memiliki nilai yang bagus dalam bidang akademik. Dalam proses operasionalnya sekolah telah memiliki fasilitas dan teknologi, yaitu adanya beberapa komputer pada ruangan lab komputer dan sejumlah komputer yang digunakan oleh pegawai TU tetapi dalam pengolahan untuk pencarian data tersebut masih kurang tepat sasaran untuk memperoleh nilai yang terbaik. Pengolahan data dalam penentuan beasiswa di SMK Madyatama hingga saat ini masih menggunakan sistem yang masih manual. Dimana belum adanya sistem yang terkomputerisasi dengan baik dalam menentukan penerimaan beasiswa yang kemudian menyebabkan munculnya beberapa masalah pada sistem manual ini. Masalah yang sering kali muncul yaitu kurang tepatnya penyaluran beasiswa terhadap siswa. Masalah seperti ini dipicu karena kurangnya ketelitian dari para penyeleksi beasiswa dalam melakukan proses seleksi terhadap si penerima beasiswa.

\section{METODOLOGI PENELITIAN}

\subsection{Metode Penelitian}

Metode penelitian yang diajukan adalah metode deskriptif adalah suatu metode penelitian yang ditujukan untuk menggambarkan fenomena-fenomena yang ada, yang berlangsung saat ini atau saat yang lampau. Penelitian ini tidak mengadakan manipulasi atau pengubahan pada variabel-variabel bebas, tetapi menggambarkan suatu kondisi apa adanya. Penggambaran kondisi bisa individual atau menggunakan angka-angka (Sukmadinata, 2006).

\subsection{Metode Pengumpulan Data}

Metode Pengumpulan Data yang digunakan dalam penelitian ini adalah: 1) Wawancara. Dalam metode ini penulis mengumpulkan data penelitian dengan bertanya langsung kepada bagian HUMAS SMK Madyatama Palembang, 2) Observasi. Metode ini dilakukan dengan cara mengamati langsung keadaan dan kegiatan pada SMK Madyatama Palembang sebagai objek guna mendapatkan keterangan yang akurat, 3) Kepustakaan. Mengumpulkan data dengan cara mencari dan mempelajari data-data dari buku-buku ataupun dari referensi lain yang berhubungan dengan penulisan laporan penelitian sekripsi. Buku yang digunakan penulis sebagai referensi, adapun metode yang digunakan penulis dalam merancang dan mengembangkan dapat dilihat pada daftar pustaka.

\subsection{Metode Pengembangan Sistem}

Metode pengembangan sistem yang dipakai untuk merancang sistem informasi akademik pada SMK Madyatama Palembang yang berbasis web ini, penulis menggunakan metode prototype. Metode ini 
merupakan salah satu metode yang banyak digunakan dalam pengembangan perangkat lunak. Metode prototype (Pressman, 2010) merupakan evolutionary models are iterative, they are characterized in a manner that enables you to develop increasingly more complete versions of the software. Pengembang perangkat lunak harus memperhatikan tahapan dalam metode prototyping agar software finalnya dapat diterima oleh penggunanya. Tahapan-tahapan dalam prototyping tersebut adalah 1) Komunikasi, 2) Perencanaan, 3) Permodelan Perancangan, 4) Konstruksi/Pembentukan Prototype, dan 5) Penyerahan Sistem.

\section{HASIL}

Berdasarkan hasil penelitian yang dilakukan hasil akhir dari semua kegiatan dan tahapan-tahapan pengembangan sistem yang telah dilakukan merupakan penerapan dari rancangan-rancangan yang telah diuraikan pada bab sebelumnya yang terdiri dari desain file, desain input, dan desain output. Bahasa pemrograman yang digunakan dalam membangun program ini adalah PHP.

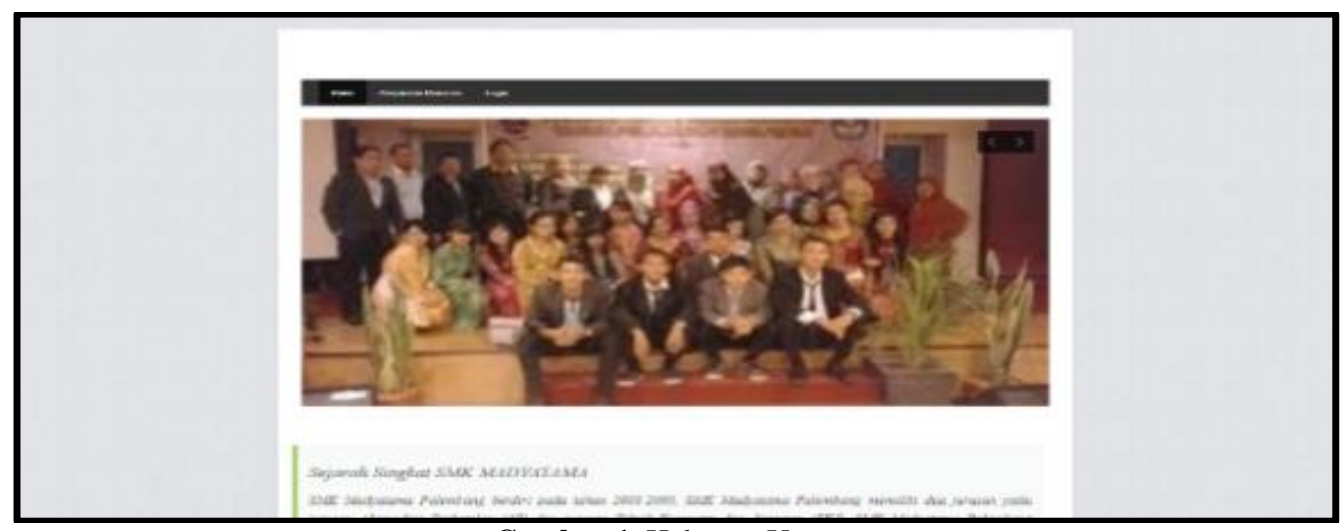

Gambar 1. Halaman Utama.

\subsection{Halaman Utama}

Form tampilan umum halaman yang berfungsi menampilkan halaman utama yang ada pada tampilan umum yang menampilkan tentang sejarah dan visi misi dari SMK Madyatama Palembang pada sistem pendukung keputusan (SPK) penentuan beasiswa pada SMK Madyatama Palembang yang terletak pada halaman umum dan dapat dilihat oleh siswa ataupun pengguna lainnya.

\subsection{Halaman Persyaratan}

Form ini merupakan halaman yang berfungsi menampilkan data-data persayatan beasiswa yang dapat dilihat oleh siswa yang ada pada tampilan SPK penentuan penerima beasiswa. Persayaratannya berupa data nilai raport, surat keterangan penghasilan orang tua, surat keterangan tidak mampu, jumlah saudara, jarak kesekolah, ke sekolah menggunakan kendaraan umum atau pribadi.

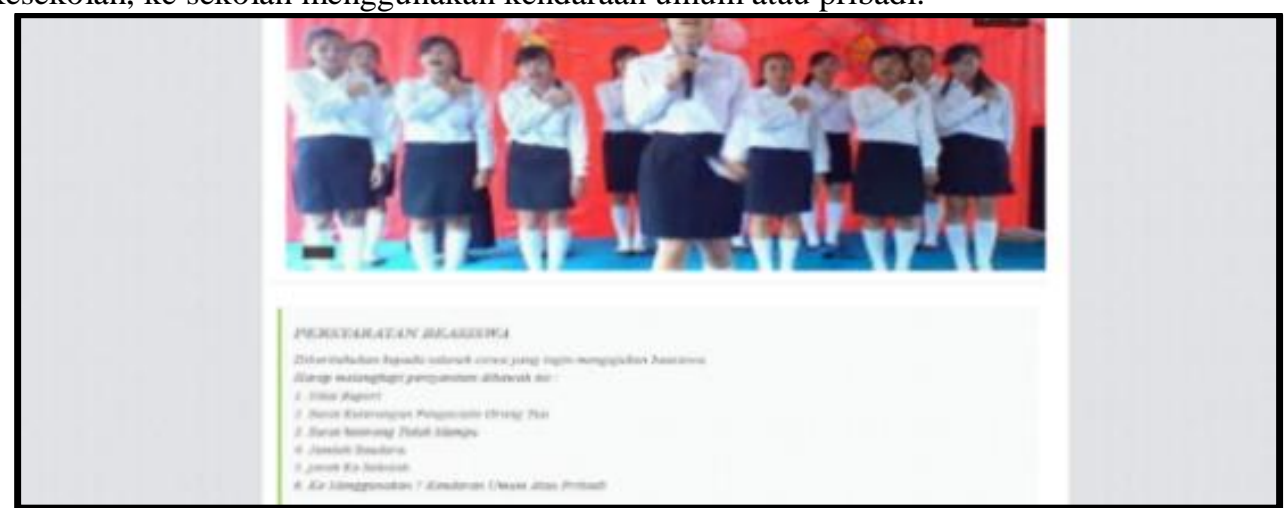

Gambar 2. Halaman Persyaratan. 


\subsection{Halaman Input Data Siswa}

Form tampilan input data siswa adalah halaman yang menampilkan input-an data siswa yang dilakukan oleh admin pada sistem pendukung keputusan penentuan penerima beasiswa pada SMK Madyatama Palembang.

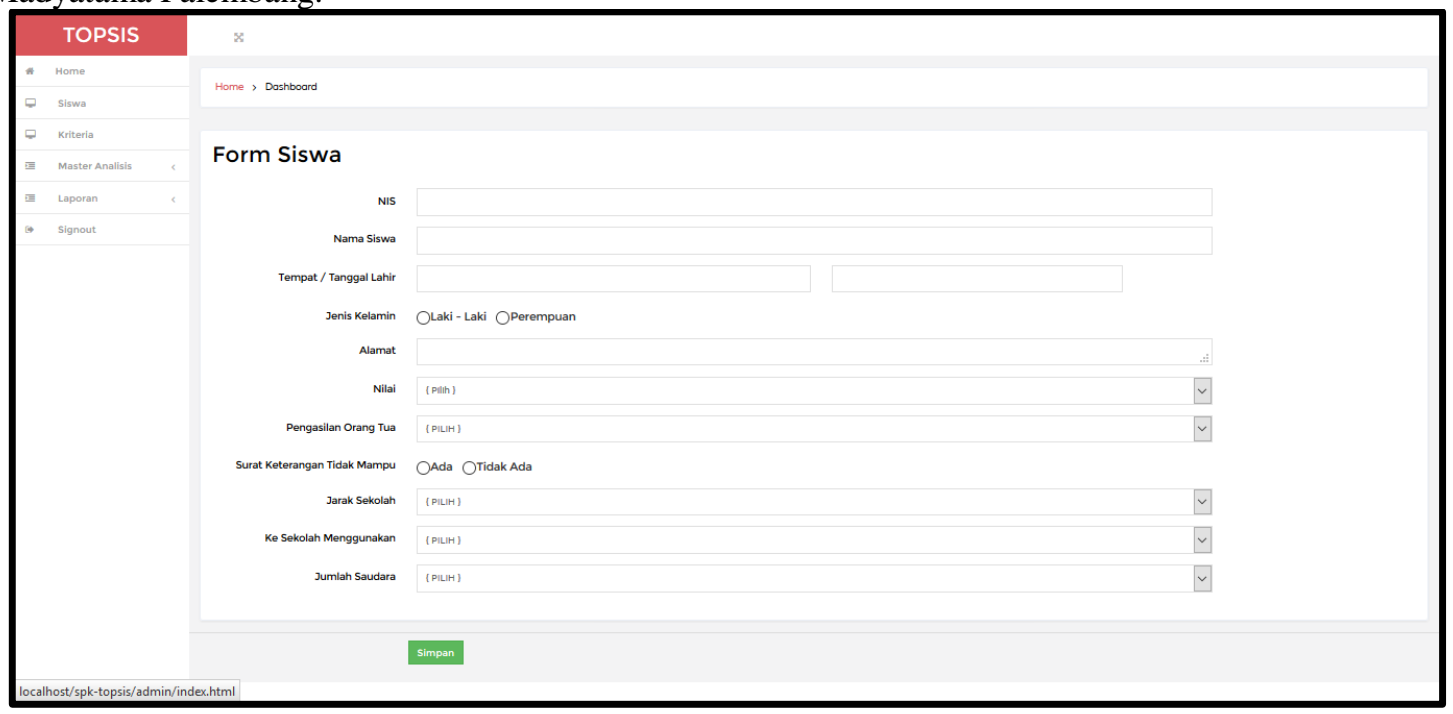

Gambar 3. Halaman Input Data Siswa.

\subsection{Halaman Input Data Kriteria}

Form tampilan data kriteria adalah halaman yang menampilkan input-an data kriteria penerimaan beasiswa yang di-input-kan oleh admin pada sistem pendukung keputusan penentuan penerima beasiswa pada SMK Madyatama Palembang.

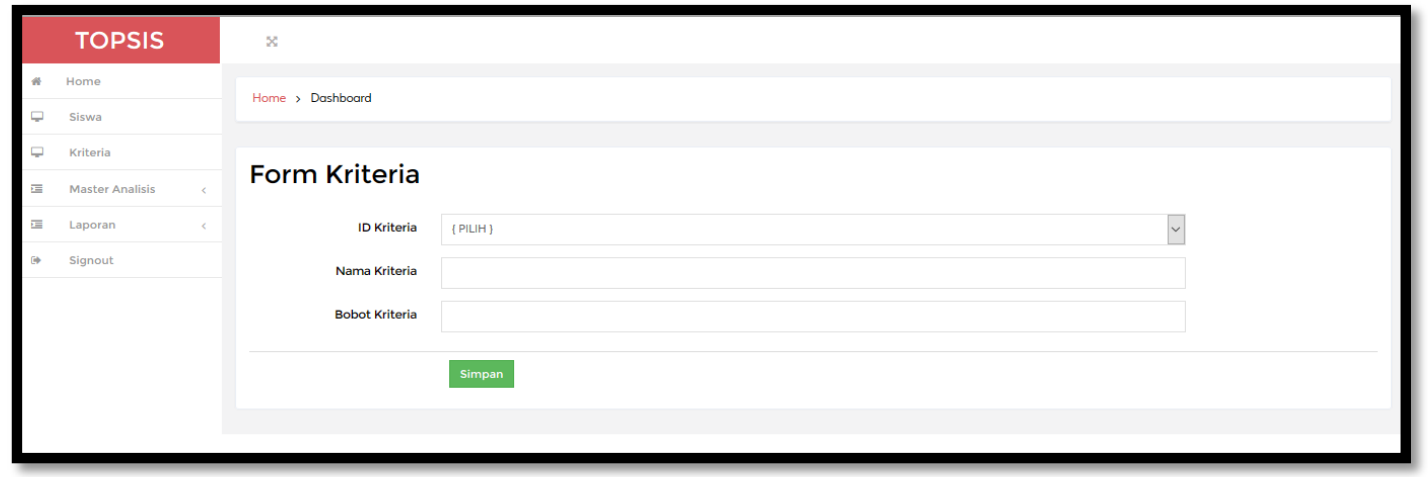

Gambar 4. Halaman Input Data Kriteria.

\subsection{Halaman Analisis TOPSIS}

Form tampilan analisis TOPSIS adalah halaman yang menampilkan sistem penilaian dari sistem pendukung keputusan disesuaikan dengan kriteria yang mejadi acuan dalam sistem pendukung keputusan penentuan penerima beasiswa pada SMK Madyatama Palembang. 


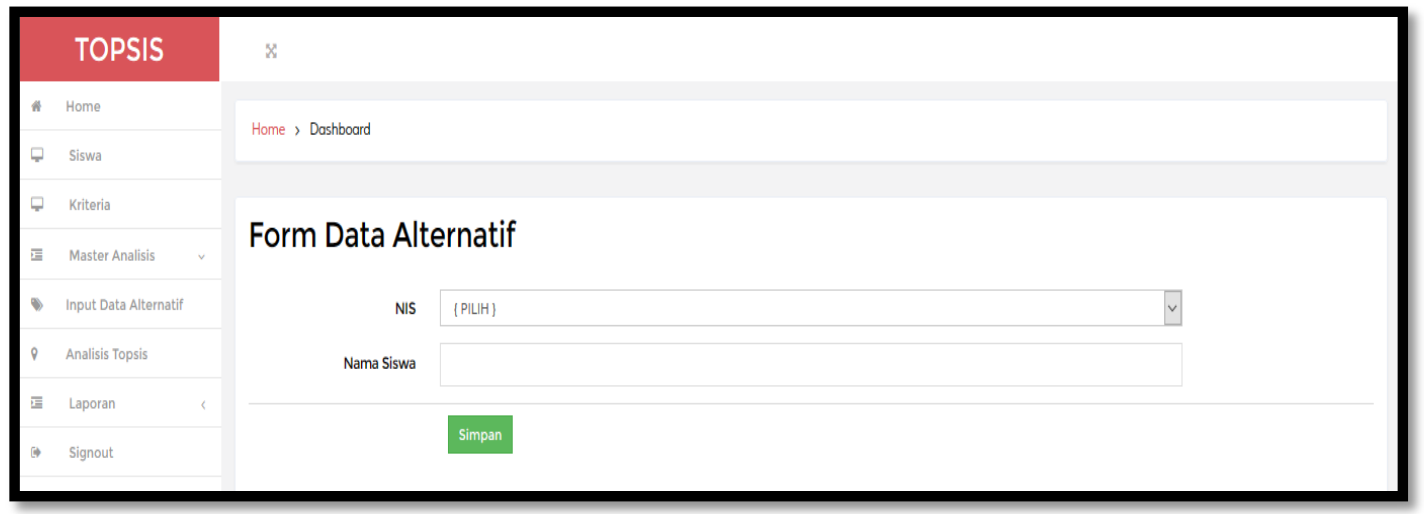

Gambar 5. Halaman Input Data Kriteria.

\subsection{Halaman Hasil Penilaian}

Form tampilan hasil penilaian admin adalah halaman yang menampilkan hasil dari penilaian yang sudah diberikan berdasarkan sistem pendukung keputusan dan kriteria yang sudah diinputkan pada sistem pendukung keputusan penentuan penerima beasiswa pada SMK Madyatama Palembang, sehingga menghasilkan hasil yang berdasarkan perengkingan dari nilai tertinggi.

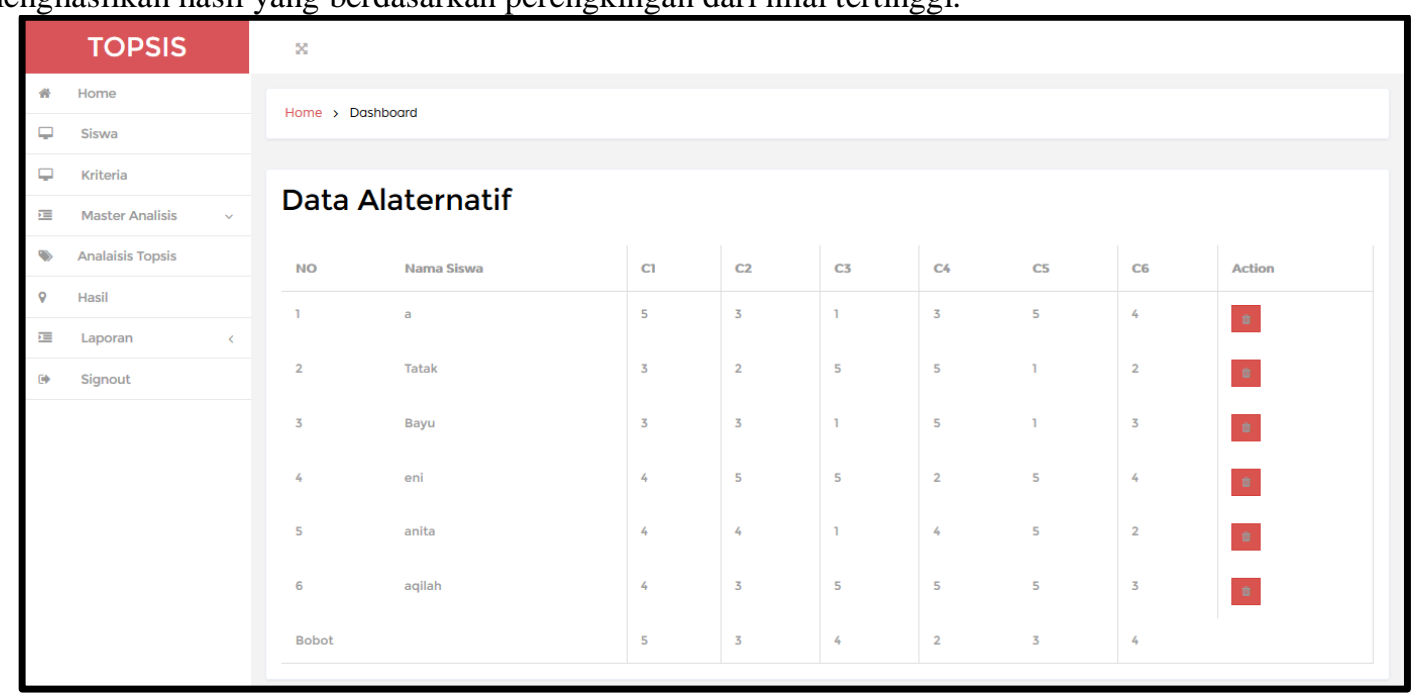

Gambar 6. Halaman Input Data Kriteria.

Dalam metode penelitian ini ada bobot dan criteria yang dibutuhkan untuk menentukan siapa yang akan terseleksi sebagai penerima beasiswa. Berdasarkan wawancara dengan narasumber, berikut adalah kriteria penialaian yang digunakan dalam penelitian ini: 1) $\mathrm{C} 1$ : Nilai, 2) $\mathrm{C} 2$ : Penghasilan orang tua, 3) C3 : Surat keterangan tidak mampu, 4) C4 : sekolah menggunakan apa, 5) C5 : Jumlah saudara, dan 6) C6 : Jarak ke sekolah.

\subsection{Hasil Pemeringkatan}

Form tampilan hasil perengkingan admin adalah halaman yang menampilkan hasil dari hasil penilaian dan direngkingkan yang sudah dianalisis dan dinilai berdasarkan sistem pendukung keputusan dan kriteria yang sudah diinputkan pada sistem pendukung keputusan penentuan penerima beasiswa pada SMK Madyatama Palembang, sehingga menghasilkan hasil yang berdasarkan perengkingan dari nilai tertinggi pada SPK penentuan penerima beasiswa pada SMK Madyatama Palembang. 


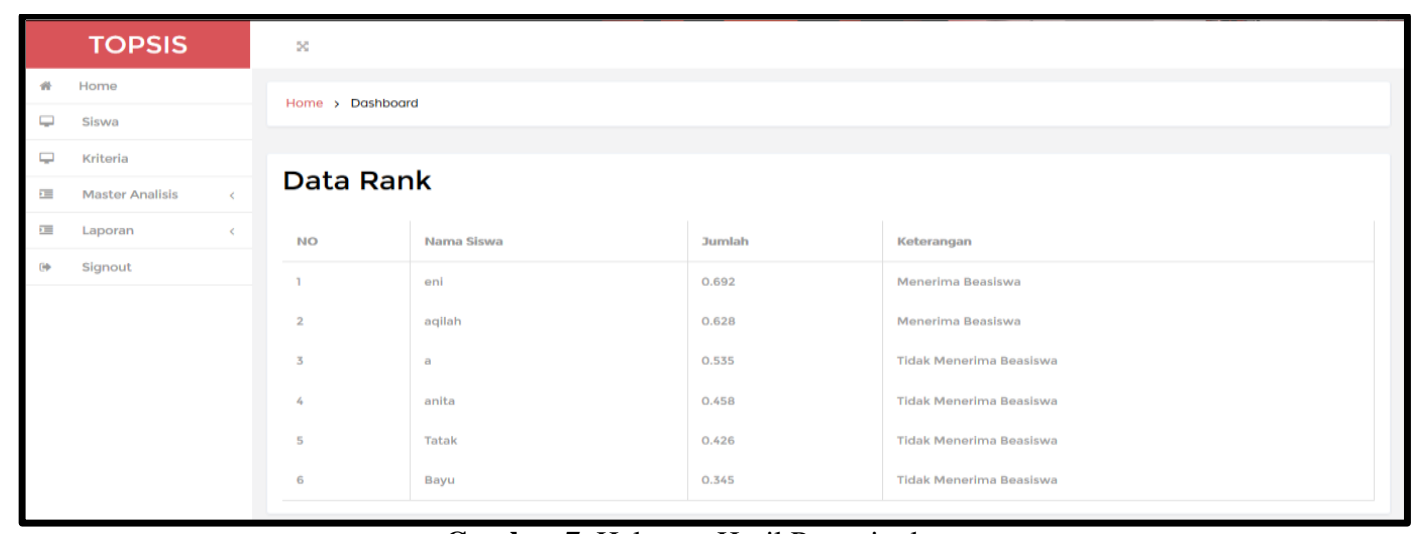

Gambar 7. Halaman Hasil Pemeringkatan.

\section{SIMPULAN}

Berdasarkan dari hasil penelitian dan analisis yang dilakukan penulis pada SMK Madyatama Palembang, penulis dapat mengambil kesimpulan:

1) Dengan adanya sistem pendukung keputusan penentuan penerima beasiswa pada SMK MadyatamaPalembangwebsite ini, untuk membantu pihak sekolah dalam penentuan dan mengambil keputusan siswa yang berhak mendapatkan beasiswa.

2) Dengan adanya sistem pendukung keputusan penentuan penerima beasiswa pada SMK Madyatama Palembang website ini dapat membantu pihak sekolah dalam melakukan pemberkasan yang terkadang membutuhkan waktu yang cukup lama dengan sistem ini pihak sekolah hanya perlu mencari daftar siswa yang telah terinput dalam komputer dan dari data yang sudah dinputkan oleh admin.

3) Sistem pendukung keputusanini diharapkan dapat memudahkan AMIK Bina Sriwijaya Palembangdalampengelolaan data-data penerimaan dosen.

4) Dengan adanya sistem pendukung keputusan penentuan penerima beasiswa pada SMK Madyatama Palembang website ini dapat membantu dan memudahkan pihak sekolah dalam melakukan evaluasi terhadap penyeleksian penerimaan beasiswa.

\section{DAFTAR PUSTAKA}

Ariani, A., Abdillah, L. A., \& Syakti, F. (2013). Sistem pendukung keputusan kelayakan TKI ke luar negeri menggunakan FMADM. Jurnal Sistem Informasi (SISFO), 4(5), 336-343.

Fan, C. K., \& Cheng, S. W. (2009). Using analytic hierarchy process method and technique for order preference by similarity to ideal solution to evaluate curriculum in department of risk management and insurance. $J$ Soc Sci, 19(1), 1-8.

Hermawan. (2005). Sistem Pendukung Keputusan. Jakarta: Gramedia Pustaka Utama.

Jumiati, Y. (2013). Sistem Pendukung Keputusan Seleksi Penerima Beasiswa untuk Siswa Berprestasi Menggunakan Metode TOPSIS dan PROMETHEE (Studi Kasus SMAN 2 Tambang-Kampar). Sarjana Teknik, Universitas Islam Negeri Sultan Syarief Kasim Riau, Pekanbaru. Retrieved from http://repository.uin-suska.ac.id/1111/1/2013_201324.pdf

Murniasih, E. (2009). Buku Pintar Beasiswa. Jakarta: Gagas Media.

Murti, T., Abdillah, L. A., \& Sobri, M. (2015). Sistem Penunjang Keputusan Kelayakan Pemberian Pinjaman pada PT Triprima Finance Palembang dengan Metode Fuzzy Tsukamoto. Paper presented at the Seminar Nasional Inovasi dan Tren 2015 (SNIT2015), Kalimalang, Jakarta.

Pressman, R. S. (2010). Software Engineering: A Practitioner's Approach (7th ed.). New York, US: McGraw-Hill.

Sukmadinata. (2006). Metode Penelitian. Bandung: Rosdakarya.

Umami, P., Abdillah, L. A., \& Yadi, I. Z. (2014). Sistem penunjang keputusan pemberian beasiswa bidik misi. Paper presented at the Konferensi Nasional Sistem Informasi (KNSI), STMIK Dipanegara Makassar, Sulawesi Selatan.

Wijaya, K., Wowor, H., \& Tulenan, V. (2015). Sistem Pendukung Keputusan Penerima Beasiswa dengan Metode Technique For Order Preference By Similarity To Ideal Solution di Universitas Sam Ratulangi Manado. Jurnal Teknik Informatika Universitas Sam Ratulangi, 5(1). 